PontIFícIa UNIVERSIDADE CATÓLICA dO RIO DE JANEIRO

Análise do comportamento de consumidores alcançados por diferentes meios de comunicação:

Um estudo de caso sobre a Pizo Store

Rodrigo Albuquerque de Souza

Trabalho de Conclusão de Curso

Centro de CiÊnCIAS Socials - CCS

Departamento de AdMINISTRAÇÃo

Graduação em Administração de Empresas 
Rodrigo Albuquerque de Souza

\section{Análise do comportamento de consumidores alcançados por diferentes meios de comunicação: \\ Um estudo de caso sobre a Pizo Store}

Trabalho de Conclusão de Curso

Trabalho de Conclusão de Curso, apresentado ao programa de graduação em Administração da PUC-Rio como requisito parcial para a obtenção do título de graduação em Administração.

Orientadora: Marina Frid 
"Experiência não é o que acontece com um homem, é o que um homem faz com o que lhe acontece." (Aldous Huxley) 
Agradecimentos

Agradeço a todos os meus amigos e familiares por fazerem parte da minha vida e na construção da pessoa que sou hoje. Agradeço aos meus pais por todo esforço, carinho e paciência ao longo de toda essa jornada, sem eles nada disso seria possível. 


\section{Resumo}

Albuquerque, Rodrigo. Análise comportamental de consumidores atingidos por diferentes meios de comunicação: Um estudo de caso sobre a Pizo Store. Rio de Janeiro, 2018. Trabalho de Conclusão de Curso - Departamento de Administração. Pontifícia Universidade Católica do Rio de Janeiro.

O presente estudo teve como um dos seus objetivos a identificação dos perfis de consumidores e o plano de marketing mais eficiente para um case real. Para isso primeiro se estabeleceu quais são os canais de comunicação utilizados por seus consumidores e em seguida foram traçados os tipos de perfis de consumidores no qual a empresa atende. Também foram considerados quais fatores contribuem para a decisão de compra desses. O segundo passo foi analisar quais desses meios de comunicação garantem um maior retorno em vendas à empresa. Outro objetivo do presente estudo foi, a partir dos dados coletados, analisando os resultados obtido pelo CRM e outros relatórios gerados pela base de informações da empresa, reformular as estratégias de marketing necessárias para o aprimoramento das operações da Pizo Store, além do atendimento dos consumidores dos produtos e serviços oferecidos por aquela. A coleta dos dados foi realizada ao longo do ano de 2017, período de abertura da sociedade até o momento atual. Ao final será, com a análise dos dados coletados na pesquisa, apresentada a conclusão acerca de como a empresa deve se posicionar e gerenciar seu plano de marketing a partir da análise realizada.

\section{Palavras-chave}

Marketing - Comportamento do consumidor - planejamento de marketing planejamento de comunicação - Decisão de compra 


\section{Abstract}

Albuquerque, Rodrigo. Behavioral analysis of consumers reached by different communication media: Pizo Store report. Rio de Janeiro, 2018. Term paper Business Department. Pontifical Catholic University of Rio de Janeiro

The objective of this study was to identify the consumer profiles and the most efficient marketing plan for a real case. To do this, it was first established the communication channels used by its consumers and then the types of consumer profiles in which the company was dealt with. It was also considered which factors contribute to the purchase decision. The second step was to analyze which of these means of communication guarantee a higher return on sales to the company. Another objective of the present study was to analyze the results obtained by the CRM and other reports generated by the company's information base, to reformulate the marketing strategies needed to improve the Pizo Store's operations, as well as to serve consumers of the products and services offered by it. The data collection was carried out throughout 2017, the company's opening period up to the present moment. At the end, with the analysis of the data collected in the research, the conclusion will be presented about how the company should position itself and manage its marketing plan based on the analysis performed.

Key-words

Marketing - Consumer behavior - marketing planning - communication planning - Purchase decision 


\section{Lista de Figuras}

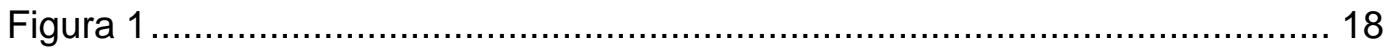

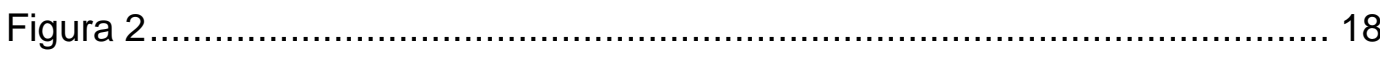

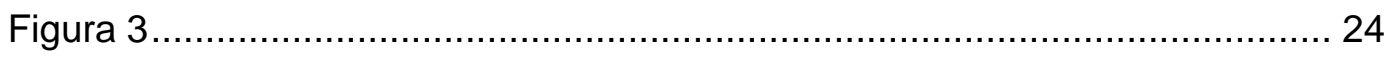

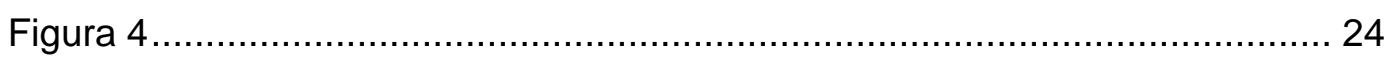

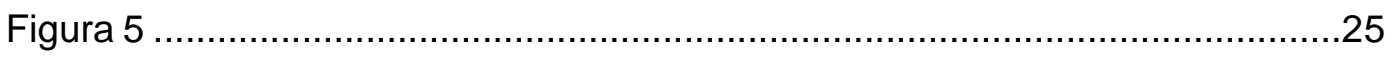


Lista de tabelas

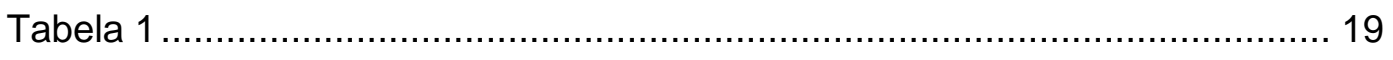

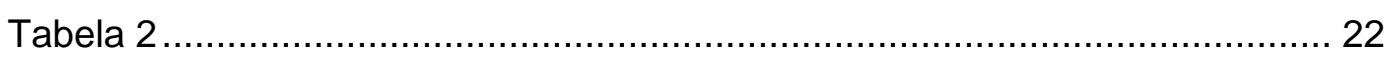




\section{Sumário}

1. Introdução 1

2. Referencial Teórico 6

2.1. Comportamento do consumidor 8

2.2. Processo de decisão de compra 10

3 . Metodologia 14

4. Apresentação e análise dos resultados 17

4.1. Perfis de consumidores identificados relacionados a cada meio de $\begin{array}{ll}\text { comunicação com o cliente: } & 19\end{array}$

4.2. Cruzamentos de dados: Meio de comunicação x orçamentos convertidos: 21

5. Conclusão 27

Referências Bibliográficas $\quad 30$ 


\section{Introdução}

O presente estudo teve como um dos seus objetivos a identificação dos perfis de consumidores e o plano de marketing mais eficiente para um case real. Esse estudo foi realizado sobre o caso da Pizo Store, uma empresa de decoração, especializada em pisos laminados e vinílicos situada no Rio de Janeiro.

A Pizo Store utiliza diversos canais de comunicação como revistas do Jornal O Globo, Facebook e campanhas de marketing no Google, para a divulgação de seus produtos e serviços. Porém, foi identificada a necessidade de ser realizada uma análise mais detalhada sobre o retorno desses canais, tendo sido tal análise nunca feita até o momento do início da elaboração desse trabalho.

Assim, o resultado obtido com a análise das questões levantadas irá contribuir para a elaboração do plano de marketing da Pizo Store, uma vez que deixarão em evidência as mídias que mais geram retorno financeiro e/ou retorno de imagem. Os dados foram coletados diretamente da empresa, sobretudo, de relatórios gerados do seu sistema de CRM (customer relationship mangament), sistema esse que gerencia todas as informações consideradas importantes à respeito do cliente e com isso facilita na hora de extração de relatórios e outras informações. O período analisado foi de janeiro de 2017 até janeiro de 2018.

A ideia central do presente trabalho, surgiu a partir da experiência na administração da Pizo Store, revendedora de pisos laminados, além de outros artigos de decoração, que foi criada após seus sócios Rodrigo e Diego identificarem uma oportunidade nesse mercado. Os dois já trabalhavam no ramo de distribuição e constantemente lidavam com os clientes e com os problemas que os mesmos enfrentavam no dia-a-dia. Dessa forma resolveram pedir demissão de seus cargos e abriram uma sociedade, a Pizo Store. A experiência obtida à frente da distribuidora de pisos laminados foi determinante para conhecer as principais dificuldades enfrentadas por seus clientes, assim como identificar alguns dos principais erros cometidos na administração das empresas. 
Os dois já possuíam na época certo conhecimento na área de administração, uma grande vantagem já que a maioria dos clientes da distribuidora não possuíam. Os perfis de clientes da distribuidora (atuais concorrentes da Pizo Store) em sua maioria eram de origem muito humilde, com baixo grau de escolaridade, e que por sua vez, por diferentes razões, não conseguiam levar suas empresas à diante, seja por uma má administração devida a falta de conhecimento na área ou por condições adversas do mercado.

O contexto mercadológico à época era de saturação, uma vez que já existiam diversas empresas neste segmento, de varejo de pisos laminados e afins. Porém em meados de 2014 tivemos a crise econômica que assolou o país trazendo diversas consequências negativas para aqueles que atuavam nesse mercado. A crise fez com que muitas dessas empresas, as quais não possuíam uma administração sólida, bem como uma saúde financeira estável, fossem obrigadas a encerrar suas atividades, por conseguinte o mercado que estava saturado passou a ter poucos agentes ativos, que poderiam oferecer serviços com qualidade a partir de uma boa estrutura.

Diante desse cenário, Rodrigo e Diego encontraram o momento perfeito para iniciar o projeto da Pizo Store. Para os dois, seria necessário constituir mais que uma sociedade que se propusesse a vender pisos laminados da mesma forma que as sociedades que tinham acabado de encerrar suas atividades estavam fazendo. Seria necessário trazer ideias novas, a fim de garantir uma boa posição de mercado.

Segundo Kotler, (2006, p. 55), posicionamento de mercado é "a ação de projetar o produto e a imagem da organização, com o fim de ocupar uma posição diferenciada na escolha de seu público-alvo". Em outras palavras, pode-se definir o Posicionamento de mercado a partir da seguinte fórmula: Segmentação + Diferenciação = Posicionamento.

A estratégia da Pizo Store se baseia em dois pilares fundamentais: atendimento diferenciado e preço justo. Seu foco é trazer inovação para segmento do varejo de pisos laminados, construindo uma marca mais jovem com uma identidade mais forte e presente. A ideia central da Pizo Store é de se tornar uma marca de referência em pisos laminados e vinílicos, assim como ser reconhecida pelo ótimo atendimento ao consumidor. 
O projeto da Pizo Store foi criado com o propósito de ser o primeiro modelo de cadeia de lojas desse segmento no estado do Rio de Janeiro. Com aspecto jovem e inovador, a marca possui como principal foco o consumidor e em como satisfazê-lo desde o início da venda até o pós-venda.

Levando em consideração que um dos focos principais da empresa para se diferenciar das demais empresas desse mercado é o atendimento do consumidor e como tornar a experiência de compra a mais satisfatória possível, se fez necessário a realização de um estudo sobre esses consumidores, seus tipos de perfis e uma análise sobre os seus comportamentos. Logo, também houve a necessidade do desenvolvimento de um plano de marketing baseado nos meios de comunicação utilizados pela Pizo Store para alcança esses consumidores. $O$ presente estudo tem exatamente como objetivo mensurar esses dados e alocalos adequadamente de acordo com os recursos disponíveis para obter os melhores resultados possíveis.

A partir disso, o primeiro passo foi a realização do levantamento de dados obtidos ao longo de todo o período de funcionamento da Pizo Store no ano de 2017, com a finalidade de conhecer sobre sua clientela. Em seguida, traçar os perfis de consumidores atendidos pela Pizo Store identificando os canais de comunicação pelos quais foram captados.

Assim, foram analisados os perfis dos clientes, tendo sido traçado um paralelo com o retorno obtido de cada um desses clientes, ao final será concluído qual a melhor forma de distribuir os recursos entre os canais de comunicação da empresa objeto da presente análise.

A Pizo Store, como a maioria das empresas do segmento, possui uma abrangente estratégia de marketing e propaganda utilizando todas as ferramentas disponíveis como que compreendem desde a utilização das redes sociais como: Instagrame Facebook, até os meios de comunicação mais tradicionais, tais como, revista do Jornal O Globo, Busdoors, portais de fornecedores e sites de busca.

Abaixo seguem alguns dados retirados dos sites: Search Engine Land, Content Trends e Hub Spot, que demonstra a importância de estar sempre investindo nos meios de comunicação. 
- $78 \%$ das pesquisas locais-móveis resultam em compras offline. (Search Engine Land, 2014)

- $36,9 \%$ investem até $10 \%$ do orçamento total de Marketing em Facebook Ads e 32,5\% investem até $10 \%$ do orçamento total de Marketing em Google Adwords. (Content Trends, 2017)

- $58 \%$ dos compradores querem falar sobre os preços na primeira chamada de vendas, enquanto $65 \%$ dos vendedores querem manter a conversa sobre os objetivos. (Hub Spot, 2016)

Pelo fato da Pizo Store ter nascido a partir de um conceito atual, acompanhando a tendência do mercado em que as sociedades estão cada vez mais conectadas aos seus consumidores, aliada ao fato de possuir um corpo de funcionários e administradores jovens, o processo de implementação do plano de negócios e marketing, bem como o volume de capital alocado para o investimento nessas ferramentas foi feito de forma natural.

No setor de varejo, não exclusivamente no segmento de decoração e pisos laminados, o público-alvo é muito amplo e diversificado, fazendo com que a estratégia para se atingir um perfil mais específico de consumidor e a melhor forma de abordagem para esse, tenha que ser bem planejada. Daí a importância de se traçar um perfil dos consumidores atingidos por cada meio de comunicação.

Logo, nota-se um padrão no comportamento do consumidor, ligado diretamente ao canal de comunicação qual o mesmo foi alcançado, dessa forma, o presente estudo tem o objetivo principal compreender melhor os fatores que influenciam na decisão de compra para cada tipo de perfil de consumidor identificado, levando em consideração o comportamento de cada um desses clientes.

Diante das considerações apresentadas, este trabalho irá abordar as estratégias adotadas e analisar os resultados concretos obtidos, entregando um feedback real do que pode ser avaliado sobre os diferentes tipos de comportamento dos consumidores. Portanto, com o objetivo de retratar o estudo de um caso real de uma empresa, com o maior embasamento possível, esse estudo limita-se à apenas o estado do Rio de Janeiro, localidade na qual a Pizo 
Store atua. Sendo assim, dados que não estejam de acordo com esse requisito não serão considerados.

Por fim, esse estudo permitirá revelar práticas de mercado que possam ser utilizadas para empresas que se encaixem no mesmo contexto da empresa objeto do presente estudo, além de propiciar ferramentas necessárias para futuras ações relacionadas ao tema.

O objetivo é demonstrar um caso real, enfatizando as estratégias utilizadas e as consequências de tais estratégias no dia-a-dia de uma sociedade em pleno funcionamento, além de transmitir um pouco da experiência e conhecimento adquirido para outras sociedades, as auxiliando a traçar novas e reformular antigas estratégias já utilizadas, a fim de obter maior retorno sobre os investimentos realizados no plano de marketing. 


\section{Referencial Teórico}

\subsection{Definições de Marketing}

Antes de se adentrar efetivamente na análise comportamental dos consumidores da Pizo Store, deve-se fazer uma revisão de conceitos de marketing e comportamento do consumidor.

Para a Associação Americana de Marketing, (2013) pode-se definir o marketing como: "Marketing é a atividade, conjunto de instituições e processos para criar, comunicar, entregar e trocar ofertas que tenham valor para consumidores, clientes, parceiros e sociedade em geral".

Em outras palavras, a utilização do marketing na administração seria estudo destinado a escolher mercados-alvo, obtendo, mantendo e multiplicando os clientes por meio da criação, entrega e comunicação de um valor superior para os clientes (Kotler, Keller, 2006).

Tem-se, pois, que o conceito de marketing é fluido. Uma vez que possui a necessidade de atualização constante, faz parte de sua essência. Para Boone e Kurtz, (2009) a etimologia da palavra marketing abrange amplas ideias e atividades, contudo muitas vezes tal conceito é diminuído a uma simples propaganda e vendas de produtos, tornando um senso comum de que o marketing somente ocorre no momento em que o produto já está terminado. Ainda segundo os autores, o "marketing também envolve analisar as necessidades do consumidor, garantir informações precisas para desenhar ou produzir produtos ou serviços que estão de acordo com as expectativas dos consumidores e fornecedores" Boone e Kurtz (2009, p. 9). Esta ideia é corroborada por Las Casas (2012) ao dizer que o marketing engloba todas as fases relacionadas à troca, com o intuito de satisfazer os desejos dos consumidores: 
engloba todas as atividades concernentes às relações de troca, orientadas para a satisfação dos desejos e necessidades dos consumidores visando alcançar determinados objetivos de empresas ou indivíduos e considerando sempre o ambiente de atuação e o impacto que essas relações causam no bem-estar da sociedade (Las Casas, 2012 p.10).

Neste mesmo sentido Churchill e Peter (2000, p.4) indicam que o "marketing é o processo de planejar e executar a concepção, estabelecimento de preços, promoção e distribuição de ideias, produtos e serviços a fim de criar trocas que satisfaçam metas individuais e organizacionais". Alargando um pouco mais essa definição de marketing, pode-se dizer que o marketing seria, nada mais nada menos, que a entrega de uma satisfação para o consumidor ou cliente e forma de algum benefício que deseje. (Kotler, Armstrong, 2003).

Sendo assim, a constante busca das organizações em satisfazer os seus consumidores relaciona-se diretamente com a capacidade em como demonstrar, otimizar e estimular para aqueles consumidores todos os benefícios em consumirem seus produtos, tendo sempre como ponto de partida as necessidades e desejos do público estipulado como alvo.

A junção do valor e satisfação, desde que percebidos pelo cliente, é o que vai colocá-lo na direção da escolha, conforme asseveram Kotler e Keller: "O produto ou oferta alcançará êxito se proporcionar valor e satisfação ao compradoralvo. O comprador escolhe entre diferentes ofertas com base naquilo que parece proporcionar o maior valor" (Kotler, Keller, 2006, p.33).

Nesse contexto, Las Casas (2007) acredita que o processo da oferta do valor é o que chama atenção dos clientes, deixando, assim, de concentrar somente no produto ou serviço oferecido. Tal percepção acima, se torna cada vez mais evidenciada pelos clientes. Ou seja, os clientes ligam mais para o valor da ofertado pelo serviço ou produto que a satisfação, pois na visão de Kotler e Keller, o valor atrativo faz com que os consumidores busquem conhecer melhor o produto ou o serviço ofertado:

Os clientes estão exigindo cada vez mais qualidade e serviço superiores, além de alguma customização. Eles percebem menos diferenças reais entre produtos e mostram menos fidelidade a marcas. Eles também podem obter muitas informações sobre produtos por meio da Internet e de outras fontes, o que permite que comprem de maneira mais racional. Os clientes estão 
mostrando maior sensibilidade em relação ao preço em sua busca por valor (Kotler, Keller, 2006, p.48).

Sendo assim, para se reter clientes deve-se somar a satisfação e valor, como bem asseveram Kotler e Keller "Já não basta simplesmente satisfazer clientes. É preciso encantá-los" (Kotler, Keller, 2006, p.55).

E continuam: "Satisfação consiste na sensação de prazer ou desapontamento resultante da comparação do desempenho (ou resultado) percebido de um produto em relação às expectativas do comprador" (Kotler, Keller, 2006, p.58)

Concluindo o raciocínio acima Sheth, Mittal e Newman (2001, p.795) completam:

Para possibilitar que os profissionais do marketing sejam bem-sucedidos e alcancem a satisfação dos clientes, se faz necessário o estudo do comportamento do consumidor, que permite conhecer o que querem e desejam os consumidores, e ainda o modo como estes tomam suas decisões de compra e utilizam os produtos e serviços.

\subsection{Comportamento do consumidor}

O comportamento do consumidor, na visão de Solomon (2011, p.33) pode ser definido como "o estudo dos processos envolvidos quando indivíduos ou grupos selecionam, compram, usam ou descartam produtos, serviços, ideias ou experiências para satisfazer necessidades e desejos".

Compreende-se modernamente o conceito de necessidade como um motivo biológico básico, assim como o desejo de modo como nos foi ensinado pela sociedade para satisfazer essa tal necessidade.

Logo, têm-se que a necessidade já existia anteriormente. Dessa forma, a tarefa dos profissionais que atuam com o marketing será apenas recomendar modos de satisfazer as necessidades os indivíduos (consumidores) a partir da identificação daquela. Ou seja, o marketing não tem como objetivo criar tais necessidades, mas tão somente fazer com que a consciência do consumidor tome ciência de sua existência (Solomon, 2011, p 33.). 
Para Churchill e Peter (2000), os desejos de consumo se iniciam com a percepção de uma necessidade, sendo um impulso interior para atendê-la, criando a chamada motivação, devendo ser o papel dos profissionais do marketing saber o que motiva os clientes para conseguirem atendê-los.

Já, Sheth, Mittal e Newman (2001, p.326) classificam a motivação em: (i) a moção ou excitação e o (ii) objeto alvo. Definindo-os como: "uma moção é um estado interno de tensão que produz ações que visam reduzir esta tensão. Um objeto-alvo é algo no mundo externo cuja aquisição vai reduzir a tensão".

Contudo, a abordagem mais influente sobre a motivação é de autoria de Abraham Maslow, denominada como a hierarquia de necessidades de Maslow, tendo sido originalmente desenvolvida para compreender o crescimento pessoal. Ocorre que, com o passar dos anos, os profissionais do marketing adaptaram esta abordagem a fim de utilizá-la no estudo da motivação dos consumidores (Solomon, 2011).

Com base nessa hierarquia de Maslow, além do aprofundamento de estudos nesta seara, os profissionais de marketing descobriram formas eficientes de satisfazer os desejos e necessidades existentes dos consumidores.

Sendo assim, o estudo do comportamento do consumidor tem o intuito de melhor entender a percepção do consumidor para os profissionais que atuem com vendas, munidos destes dados, possa perceber as necessidades de cada consumidor, conseguindo influenciar os hábitos dos consumidores.

Para Solomon (2001) percepção pode ser compreendida como o processo físico-químico de reações pelo qual as pessoas selecionam, organizam e interpretam as sensações, sendo estas imediatas aos receptores de cada indivíduo, promovendo uma experiência sensorial, que vão desde a percepção dos olhos, ouvidos, nariz, boca e dedos a outros estímulos considerados básicos como a luz, a cor, o som, os odores e as texturas.

Logo, a percepção do consumidor acima descrita vai além da mera relação destes estímulos com o ambiente, mas engloba também a condição interior do indivíduo, entretanto como é impossível para qualquer indivíduo prestar atenção 
ao mesmo tempo a todos estes estímulos, a maioria destes o cérebro humano acaba por filtrá-lo.

Justamente este processo de filtragem realizado pelo cérebro de qualquer indivíduo é chamado de atenção seletiva, devendo para esta ação específica do cérebro os profissionais de marketing e vendas devem voltar todas a suas atenções (Kotler, Keller, 2006, p. 58).

Por todo o explanado, percebe-se que o comportamento do consumidor é de grande relevância para o presente estudo, tendo em vista que um de seus objetivos é identificar os perfis de consumidores e seus comportamentos, além de correlaciona-los aos meios de comunicação a partir dos quais foram gerados.

No âmbito das classes sociais, será procedida a análise de maneira generalizada, sem ser focada em sua renda, visto que este não é o critério principal para a análise. O intuito, aqui, é apenas estabelecer quais os fatores que realmente contribuam e que possuam relevância para a pesquisa necessária para embasar o presente trabalho.

Neste trabalho, os comportamentos de compra dos clientes da Pizo Store, alcançados por diferentes mídias serão analisados pelo grau de envolvimento com a marca. O produto/serviço comercializado pela empresa é entendido como um produto que possui médio envolvimento do consumidor com a compra. O que difere o maior ou menor envolvimento do cliente na compra é o objetivo dele ao adquirir o produto. Trata-se de um produto cuja compra é pensada, levando em consideração tempo, custo e atendimento.

\subsection{Processo de decisão de compra}

A teoria acerca do processo de compra pelos consumidores mais aceita, dentre a maioria dos autores do tema, é a de cinco etapas, que expressam cinco momentos diferentes no momento em que o consumidor se prepara para adquirir um produto ou serviço, são elas: (i) reconhecimento do problema, (ii) busca de informações, (iii) avaliação de alternativas, (iv) decisão de compra e (v) comportamento pós-compra (Kotler, Keller, 2006; Solomon, 2001; Boone, Kurtz, 
2009; Sheth, Mittal, Newman, 2001), abaixo as etapas mencionadas de forma mais detalhada.

Reconhecimento do Problema: o procedimento de compra começa, em si, no momento em que o consumidor tem a percepção de um problema ou uma necessidade. O consumidor se vê diante de um gap entre o que deseja e a necessidade (Boone, Kurtz, 2009).

Busca de Informações: nesta etapa o consumidor inicia sua pesquisa pelo ambiente ou segmento que o interessa em busca de informações adequadas para Ihe assistir em sua tomada de decisão. Cabe a ressalva, aqui, que quanto mais interessado for o consumidor existe uma tendência maior a buscar mais informações e detalhamento destas, a depender do que o consumidor deseja comprar. (Solomon, 2001).

Avaliação de Alternativas: A partir da coleta de informação e dados, os consumidores passam para a próxima etapa, qual seja avaliar as maneiras de satisfazer as necessidades e desejos percebidos por eles. (Kotler, Keller, 2006).

Decisão de Compra: após a avaliação de alternativas, o consumidor passa para decisão efetiva se adquire o produto ou serviço ou não. De acordo com os especialistas Sheth, Mittal e Newman (2001) essa fase decisória pode ser classificada em três ou outras subclasses: (i) identificação da escolha (conclusão das alternativas), (ii) intenção de compra (verificação se o orçamento ou os parâmetros continuam atrativos) e (iii) implementação da compra (como e quando pagar).

Comportamento Pós-Compra: aqui, nesta última etapa, ocorre o chamado efeito binário, pois o consumidor terá apenas dois sentimentos: satisfação com relação a mudança da sua situação anterior ou a insatisfação (Boone, Kurtz, 2009). 


\subsection{Plano de marketing da Pizo Store}

Após abordar como funciona todo o processo de compra pelo consumidor, desde aspectos fisiológicos a psicológicos, passa-se a abordar um pouco sobre o plano de marketing implementado pela Pizo Store.

"propaganda ruim é aquela que fala do produto. A boa é a que mostra o consumidor e seus anseios em relação ao produto" (WILLIANS, 1999, p.212)

A citação acima define bem um pouco dos valores da Pizo Store, pois coloca à frente o consumidor e um plano de marketing com foco no mesmo, visando atendê-los com excelência. Embora a empresa possua um preço maior do que a maioria de seus concorrentes, porém devolve aos seus consumidores um serviço, bem acima dos oferecidos pelos concorrentes, fazendo com que o preço pago a mais seja condizente com a qualidade do serviço oferecido.

Para Kotler, valorizar os clientes é, por si só, uma verdadeira estratégia de marketing (2006). Ainda seguindo o pensamento de Kotler, "satisfação consiste na sensação de prazer ou desapontamento de uma pessoa resultante da comparação entre o desempenho (ou resultado) percebido de um produto e suas expectativas" (2002, p. 42).

Já Cobra (2009), afirma que a lealdade de um cliente ou a fidelização do mesmo à uma empresa não depende da satisfação do produto e/ou serviço, pois afinal, um cliente nunca está totalmente satisfeito.

Podemos entender que há diversos entendimentos e fatores a serem considerados no relacionamento entre a empresa e o cliente. Principalmente nos dias atuais, onde a variedade de ofertas é muito grande e na maioria dos casos a percepção da diferenciação é cada vez mais difícil de ser notada pelo consumidor.

A Pizo Store procura sempre a maior comodidade do cliente, agregando o máximo de valor possível ao produto e serviço vendido. A diferenciação da 
empresa para as demais concorrentes é exatamente o fato de a Pizo Store ter uma equipe sempre à disposição do cliente para sanar suas dúvidas, fornecendo o suporte, auxílio e informações que porventura possam precisar.

Dessa forma, o cliente é mantido informado do começo ao fim da venda ou da prestação de serviço, sendo informando o dia exato que o material será entregue, o dia da instalação, tudo isso com a maior antecedência possível, ao final o cliente/consumidor ainda é questionado à respeito do serviço (pós-venda), fazendo com que receba um atendimento personalizado, exatamente como posto no plano de marketing da empresa. 


\section{Metodologia}

Para a realização da análise do presente estudo, procurou-se entender os perfis de clientes da Pizo Store alcançados por diferentes mídias. Situada no Rio de Janeiro, logo seus clientes também são da mesma região. Os dados para a elaboração desse trabalho foram retirados diretamente da empresa, sobretudo, seus relatórios gerados pelo sistema de CRM. Para melhor interpretação de dados e também para uma futura comparação, foi decidido que o melhor era realizar o estudo sobre todo o período de 2017, no caso de 01 de janeiro de 2017 até 31 de dezembro de 2017. Já a análise dos relatórios retirados foi feita durante o mês de abril e Maio de 2018. Os critérios escolhidos para utilização do método de coleta de dados que foi realizado no presente trabalho são: a pertinência dos dados, bem como o nível de confiabilidade dos mesmos.

A delimitação dos critérios mencionados acima é de extrema importância para que a tomada de decisão reflita exatamente os resultados apresentados, devendo tais dados serem íntegros, caso contrário o conceito de pesquisa e coleta de dados perde todo o seu sentido.

Os relatórios que foram considerados importantes para o estudo de caso, foram os relatórios: Ticket médio, Ligações semanais e Ligações Gerais, gênero dos consumidores da Pizo Store, além da faixa etária predominante e também o turno no qual são feitas as ligações. Todas essas informações são de extrema relevância para que seja realizado a análise dos perfis de consumidores e posteriormente cruzado com os dados de investimentos de marketing e características das mídias utilizadas, assim, conseguindo embasar as conclusões finais e definir a melhor estratégia para o plano de marketing da empresa.

A estratégia de marketing e administração da Pizo Store baseia-se em unificar e 
alinhar da melhor forma possível todas as informações analisadas, tanto do comportamento do consumidor quanto os canais de comunicação de um modo geral e com isso elaborar a estratégia mais adequada para o melhor atendimento para cada um desses consumidores, gerando o maior número de conversões possíveis.

Os objetivos estratégicos devem ser muito bem definidos pela Pizo Store, para que possam ser analisados com cuidado e assim escolher a estratégia que melhor sirva ao foco e objetivos traçados pela sociedade acima. Como dito anteriormente, a Pizo Store possui como objetivo estratégico alcançar o maior número de consumidores finais, se tornar referência no mercado de pisos e em qualidade de atendimento, tornando-se, mais adiante, uma rede de lojas voltadas para a venda de pisos laminados e artigos de decoração.

Segundo Michael Porter (1989), para que uma empresa obtenha vantagem competitiva, ela deve perseguir táticas específicas e escolher o escopo dentro do qual irá alcançá-las.

O posicionamento da empresa de forma a expandir o seu mercado consumidor sem afetar os seus clientes já existentes, evitando que se torne uma concorrência ligada diretamente à empresa faz parte de sua estratégia. Porém, a estratégia principal é consolidar uma identidade no mercado, com formato jovem e inovador, uma marca que as pessoas olhem e que se identifiquem. Uma marca com competitividade de preços, mas principalmente focada na excelência no serviço entregue, estratégia competitiva de Diferenciação, uma das maiores vantagens da loja.

Por tratar-se sempre com um dos focos principais o comportamento do consumidor e a definição dos seus tipos de perfis, a empresa possui implementado em suas operações o conhecido CRM - customer relationship mangament, visando gerenciar de forma mais eficaz as informações fornecidas e conhecer melhor os seus clientes. Assim, coletar informações importantes para a definição de estratégias quanto à alocação de recursos para as mídias de comunicação utilizadas, assunto no qual será analisado nas conclusões desse trabalho. Todos os dados retirados do sistema da empresa, serão minuciosamente analisados para que não haja nenhuma divergência nas informações concluídas e os 
resultados de fato obtidos. Foram gerados relatórios a respeito do ticket médio de gastos dos consumidores, faixa etária, gêneros, quantidade de ligações e etc. 


\section{Apresentação e análise dos resultados}

A Pizo Store nasceu a partir de um profundo estudo de mercado que demonstrou a necessidade de empresas que consigam unir um atendimento personalizado, com foco total nas necessidades do consumidor ao mesmo tempo com uma visão moderna do varejo de pisos e artigos de decoração.

Para colocar em prática o conceito acima, a Pizo Store busca constantemente o contato próximo com sua clientela, além de novos clientes. A operação se desenha da seguinte forma.

Primeiro ocorre a ligação dos novos clientes. Após esse primeiro contato, com a anuência do futuro comprador, os profissionais que trabalham na Pizo Store procedem com a visitação in loco do espaço em que o produto será colocado.

A partir daí, caso o comprador chegue a um acordo com a Pizo Store, os produtos são vendidos, o que leva ao próximo passo que é a entrega do material vendido. Ato contínuo, os profissionais da Pizo Store realizam a instalação, para então, após término da colocação do piso, o cliente ser acompanhado no pósvenda, sendo indagado se há algo que o desagradou ou que possa ser melhorado, demonstrando sempre foco total no cliente e a preocupação da satisfação do mesmo quanto ao serviço prestado.

O resumo de toda a operação da empresa seria:

Cliente entra em contato com a empresa através de um de nossos meios de comunicação, posteriormente agenda uma visita ao local para a realização de um orçamento, já com as especificações da área e o produto escolhido, a venda é realizada. Assim, é elaborada a logística de entrega e de instalação do material

e posteriormente realizado um pós-venda para saber a opinião do cliente à respeito do produto/serviço prestado e a satisfação do cliente com tal. 


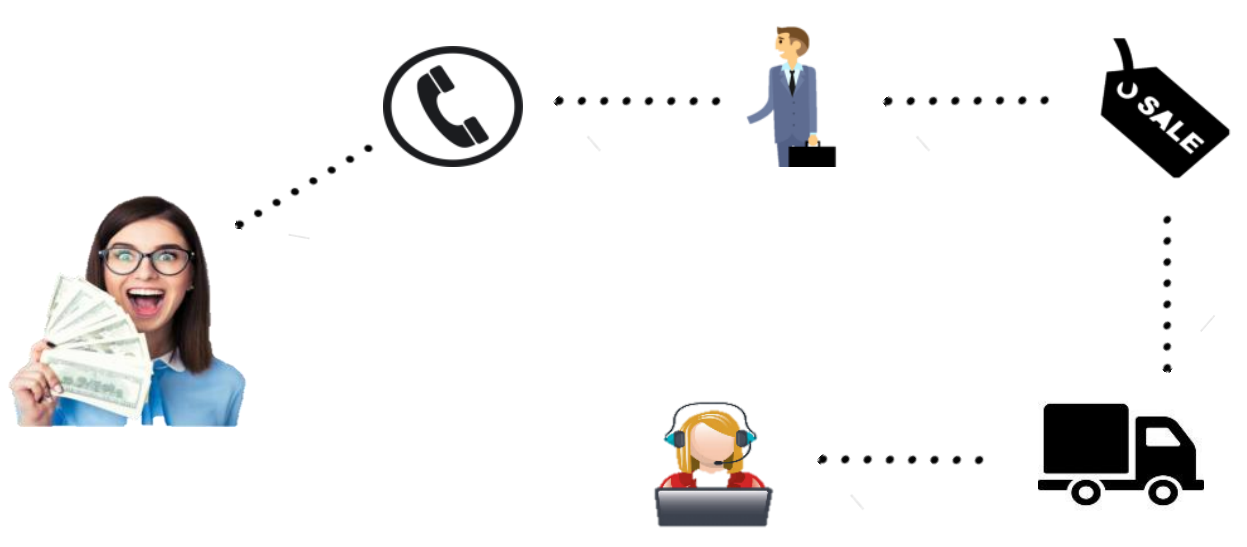

Figura 1

A Pizo Store foi constituída no início de 2017, tendo como faturamento anual, em seu primeiro ano de operação (2017): o valor bruto de $R \$ 1.128 .000,00$ (um milhão, cento e vinte oito mil reais), possuindo o Ticket médio de $\mathrm{R} \$ 3.676,82$ (três mil, seiscentos e setenta e seis reais e oitenta e dois reais), com uma média de 24 (vinte e quatro) clientes atendidos por dia. Na Figura 1, podemos observar um valor muito maior em Janeiro (1), essa disparidade deve-se à uma obra de valor alto, fazendo com que a média fuja da normalidade que pode ser observada ao longo dos outros meses (2-12) e logo para o entendimento correto das informações, o mesmo não deve ser considerada.

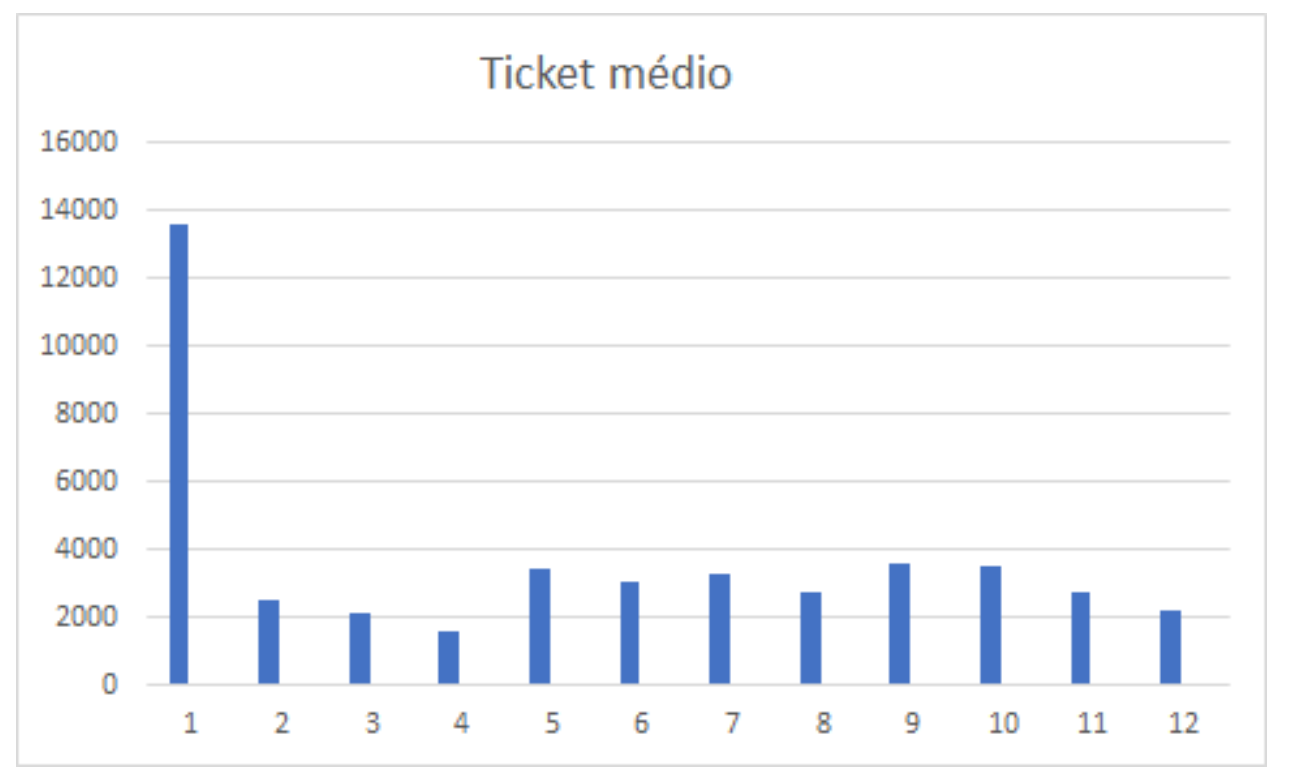

Figura 2 
Aprofundando um pouco mais ao foco do presente trabalho, a Pizo Store investe anualmente com propaganda e marketing o valor de $\mathrm{R} \$ 76.967,19$ (setenta e seis mil, novecentos e sessenta e sete reais e dezenove centavos).

\begin{tabular}{|l|l|}
\hline GOOGLE & $\mathrm{R} \$ 53.760,00$ \\
\hline REVISTA & $\mathrm{R} \$ 19.890,00$ \\
\hline FACEBOOK & $\mathrm{R} \$ 3.317,19$ \\
\hline INDICAÇÃO & \\
\hline LOJA & \\
\hline CUSTO PROP. & $\mathrm{R} \$ 76.967,19$ \\
\hline
\end{tabular}

Tabela 1

A Pizo Store, seguindo a tendência mundial de grandes corporações, que reconhecem a importância do marketing para a continuidade de seus empreendimentos, destinam em torno de $7 \%$ de sua receita atualmente para ações em marketing, porém o objetivo é aumentar para 10\% a $12 \%$ de sua receita. Assim, acredita que alcançará um equilíbrio saudável em investimento $X$ retorno.

De acordo com a tabela acima, podemos observar que para uma empresa de pequeno porte, a Pizo Store tem um investimento significativo em seu plano de marketing. Tudo isso deve-se ao fato de desde o começo da elaboração do projeto ambos os sócios já tinham em mente a importância de um bom investimento na marca da empresa e no marketing em mídias. Ao longo do ano o Google que é uma ferramenta de busca um pouco mais complexa que as demais, têm sido aperfeiçoadas para que se obtenha um maior retorno com o mesmo valor investido.

As principais mídias de veiculação são o Google, revista do jornal o Globo, Facebook e as indicações, famoso boca-boca.

\subsection{Perfis de consumidores identificados relacionados a cada meio de comunicação com o cliente:}

Perfil 1 - Facebook. Como muito bem colocado por Kotler (2006), o preço ainda é o maior atrativo aos consumidores. Tal assertiva se comprova por meio deste canal de comunicação (facebook). 
A maioria dos clientes que procuram a Pizo Store por esta rede social é atraída pelo preço ou alguma promoção oferecida. Em razão de estar focado no preço ou em alguma promoção o consumidor deste perfil não possui normalmente quase, ou nenhum interesse, em agendar uma visita pessoalmente.

Tal fato se explica pelo fato da maioria dos consumidores deste perfil possuir um menor poder de compra, pertencendo às classes, em sua maioria, C e D.

Grande volume de orçamentos com baixos valores, todos via on-line, pela pesquisa realizada percebe-se que os consumidores que procuram a empresa objeto da presente análise possui um baixo poder aquisitivo, explicado por uma menor renda, convertendo dificilmente os orçamentos em uma venda efetiva, mesmo com os preços menores, maioria jovens, explicado pela utilização intensa de redes sociais.

Perfil 2 - Revista. Público, em sua maioria, mais idoso, poder aquisitivo mais alto que o perfil 1, quantidade de visitas é proporcional ao número de ligações recebidas.

Procuram saber o preço por telefone, mas não deixam de marcar visita. $O$ que se traduz em uma taxa de conversão bastante alta.

Perfil 3 - Indicações, um dos veículos de propaganda mais importante desse segmento, o famoso "boca-a-boca".

A indicação possui uma influência fortíssima no cliente. A confiança de um amigo ou conhecido indicar, mesmo com o preço não sendo tão atrativo, inclusive maior que alguns concorrentes, os clientes dão preferência para a loja indicada.

Embora o meio de veiculação acima ainda seja despiciente, se comparado com os outros meios de veiculação, os clientes que chegam por meio de indicação possuem excelente taxa de conversão, cabe a ressalva que a Pizo Store foi constituída há pouco mais de um ano, ainda assim possui um número considerável de indicações, fruto de uma atuação forte dentre os moradores da região do Andaraí e Tijuca, responsáveis pela propaganda "boca-a-boca" 
Perfil 4 - Google + E-mail, usualmente o consumidor deste perfil chega até a Pizo Store após pesquisa no site de buscas do Google. Grande número de orçamentos, sendo uma média entre os consumidores do perfil 2 e perfil 3, com uma boa média de conversões superiores às da revista, porém inferiores à média da de indicações.

O cliente deste perfil costuma fazer uma breve pesquisa de mercado e os que possuem realmente interesse no produto/serviço realizam contato posteriormente por telefone para facilitar a comunicação.

Perfil 5 - Google + Telefone, grande quantidade de ligações, média taxa de visitas, média taxa de conversões, ambas inferiores aos perfis 3 e 4 . Principal veículo de comunicação utilizado, tem o maior percentual de custo, porém é o que dá maior retorno em geral.

Concomitantemente, no mesmo formulário, extrai-se que poucos dos entrevistados utilizam como principal meio de comunicação, ou rede social, o Facebook:

Logo, correta a conclusão de que os consumidores que procuram os serviços e produtos da Pizo Store, por meio do Facebook, possuem um menor poder de compra, o que gera uma menor conversão de orçamentos em vendas efetivas.

\subsection{Cruzamentos de dados: Meio de comunicação x orçamentos convertidos:}

Após serem traçados os perfis de cada consumidor, tendo como paradigma o meio de comunicação que o alcançou, será abordado a seguir a relação destes consumidores (de cada perfil) com a efetiva conversão dos orçamentos realizado em vendas efetivas.

Com o esse cruzamento se observou que os dados obtidos por meio do CRM da Pizo Store, em conjunto com outros relatórios específicos elaborados ao longo do ano de 2017, que houve uma grande quantidade de orçamentos realizados, porém as maiores taxas de conversão são dos clientes que chegaram 
à empresa por meio dos anúncios de revistas, chegando a atingir uma excelente média de $80 \%$ (oitenta por cento).

Inversamente proporcional a isso, pode-se perceber que o maior número de clientes chegou à Pizo Store por meio da ferramenta de busca (Google) e e-mail, porém com uma taxa de conversão muito inferior, apenas 10\% (dez por cento).

Outro ponto interessante que o CRM comprovou, o que já havia sido demonstrado com a pesquisa que traçou os perfis, por meio de formulários, como já mencionado neste trabalho, que as indicações possuem uma porcentagem alta de conversão (75\%), fazendo com que o velho "boca-a-boca" ainda seja uma eficiente proposta de marketing neste segmento.

Abaixo a tabela que consolida as informações obtidas no CRM no ano de 2017:

$\%$

$\%$

Total \% de Orçamentos/ Orçamento Quantidade Conversões

\begin{tabular}{|c|c|c|c|c|c|c|c|}
\hline Origem & 2.352 & origem & Visitas & e visitas & conversões & sobre total \\
\hline Google & 1428 & $60 \%$ & 1306 & $91 \%$ & 188 & $56 \%$ \\
\hline Revista & 96 & $4 \%$ & 76 & $79 \%$ & 61 & $18 \%$ \\
\hline Facebook & 318 & $14 \%$ & 265 & $83 \%$ & 4 & $1 \%$ \\
\hline $\begin{array}{c}\text { Indicação } \\
\text { Loja }\end{array}$ & 228 & $3 \%$ & 67 & $93 \%$ & 50 & $15 \%$ \\
\hline Não & $10 \%$ & 50 & $22 \%$ & 30 & $9 \%$ \\
\hline informado & 210 & $9 \%$ & - & - & - & - \\
\hline
\end{tabular}


A Tabela 2 visa demonstrar de forma mais clara a quantidade de contatos realizados pelos meios de comunicação utilizados pela Pizo Store e correlacionalos ao percentual de visitas e conversões, mostrando de forma mais direta quais os meios de comunicação que possuem mais conversão e quais possuem uma menor conversão. O contato do cliente realizado através da busca do Google e posteriormente o acesso ao site da empresa, que acaba por sua vez gerando um e-mail, é visivelmente o que gera mais interações com os potenciais consumidores, porém nota-se um baixo percentual de conversões se comparado ao número total de contatos realizados. Já o contato realizado via Revista O Globo e posteriormente uma ligação, é o segundo menor em quesito de contato com os clientes, porém é o que possui maior conversão.

Outros dados importantes que são utilizados no momento da elaboração do plano de marketing da Pizo Store, são as ligações que a empresa recebe tanto de clientes, quanto de consumidores em potencial.

A Pizo Store monitora também a quantidade de ligações recebidas (Figura 3) durante os dias da semana, pois assim sabe quais dias que tem o maior fluxo de ligações, além do turno (Figura4) que recebe mais chamadas e com isso alinha suas estratégias de campanhas do Google, principalmente, de acordo com essas informações. Além desse monitoramento semanal, também é feito um mensal, o qual se chegou a conclusão, por exemplo, que próximo ao dia 25 de cada mês o movimento costuma ser bem menor, vez que neste período (final do mês) os consumidores, em sua maioria, já teriam utilizado boa parte de seus salários, considerando que teriam recebido no início do mês.

Como se pode perceber da leitura dos gráficos abaixo, o maior fluxo de ligações ocorre durante o dia, principalmente no início da semana, chegando ao pico na terça-feira, decaindo no decorrer da semana. 


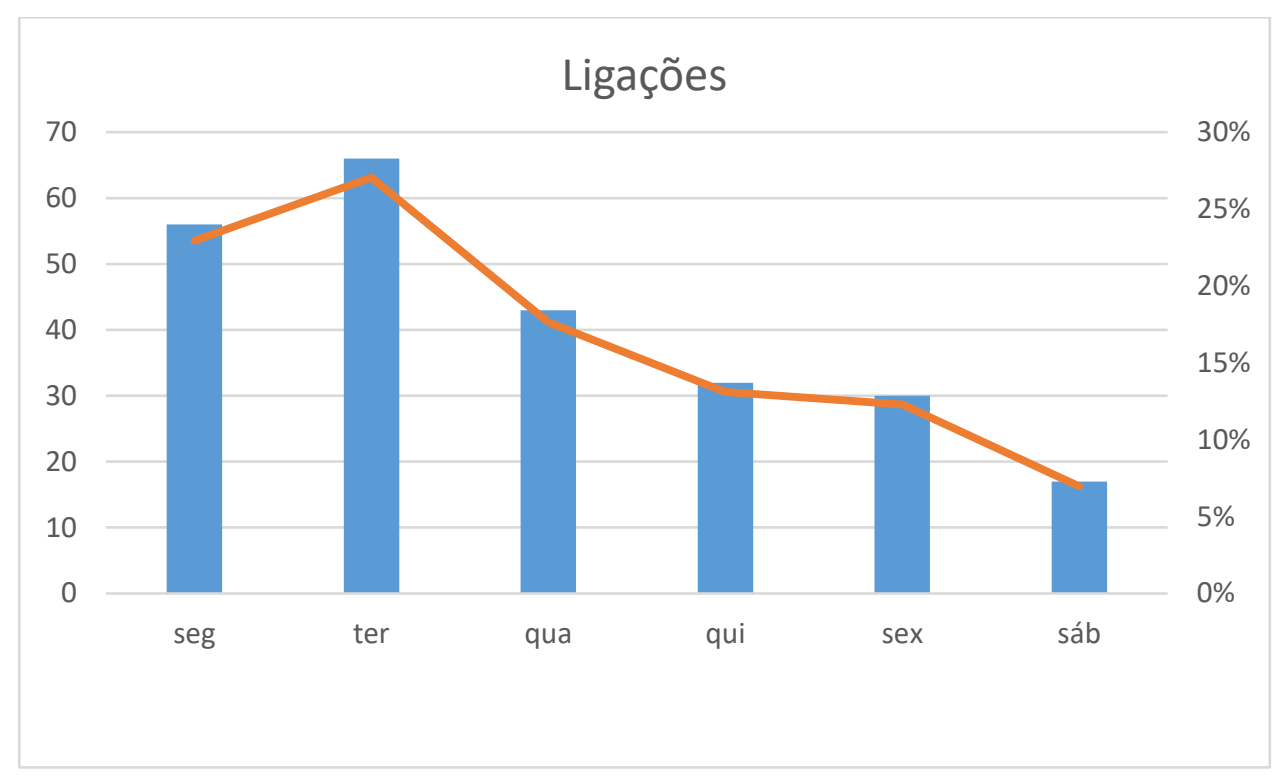

Figura 3

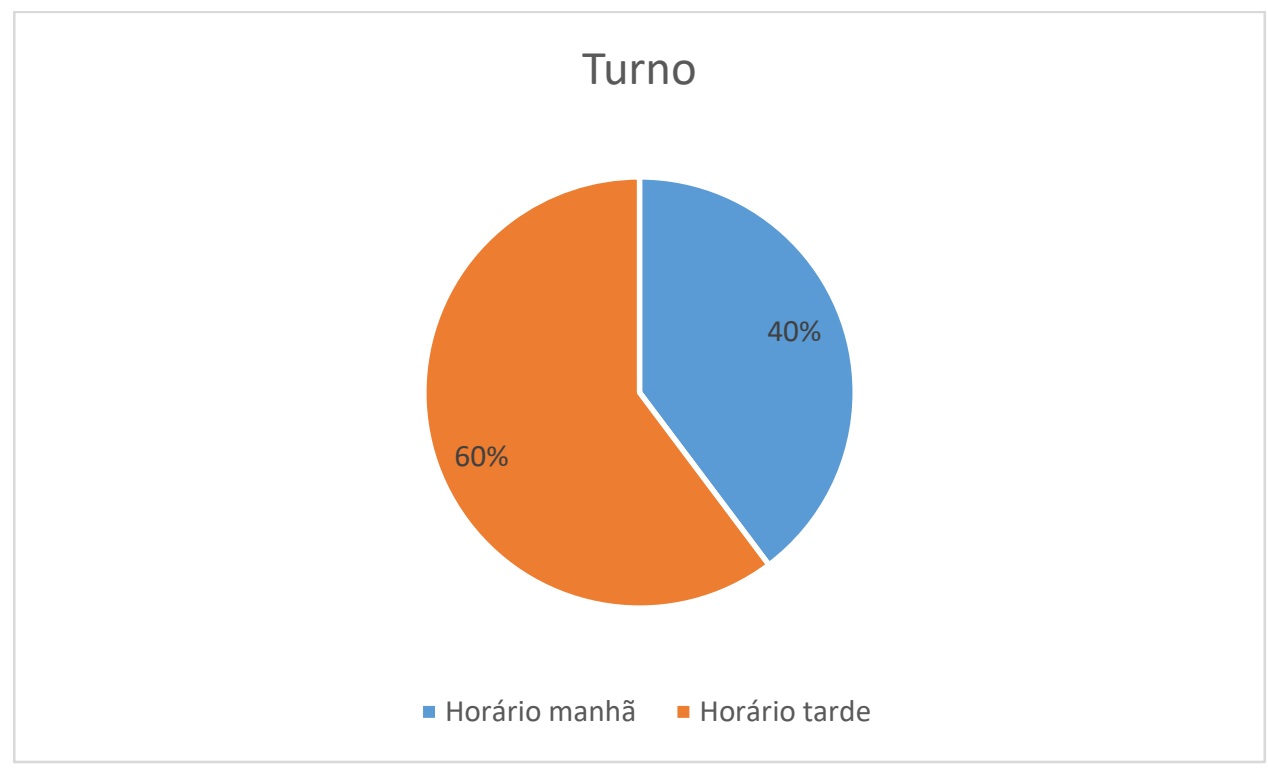

Figura 4

Realizou-se, ainda, também uma pesquisa para saber o gênero predominante (Figura 5) entre os consumidores da Pizo Store. Chegou-se à conclusão de que a maioria dos clientes da loja são do sexo feminino com $66 \%$. Pode-se tal fato ao produto oferecido, que por se tratarem de produtos voltados a decoração de interiores, que como regra geral, desperta um maior interesse no gênero feminino que ao masculino. 


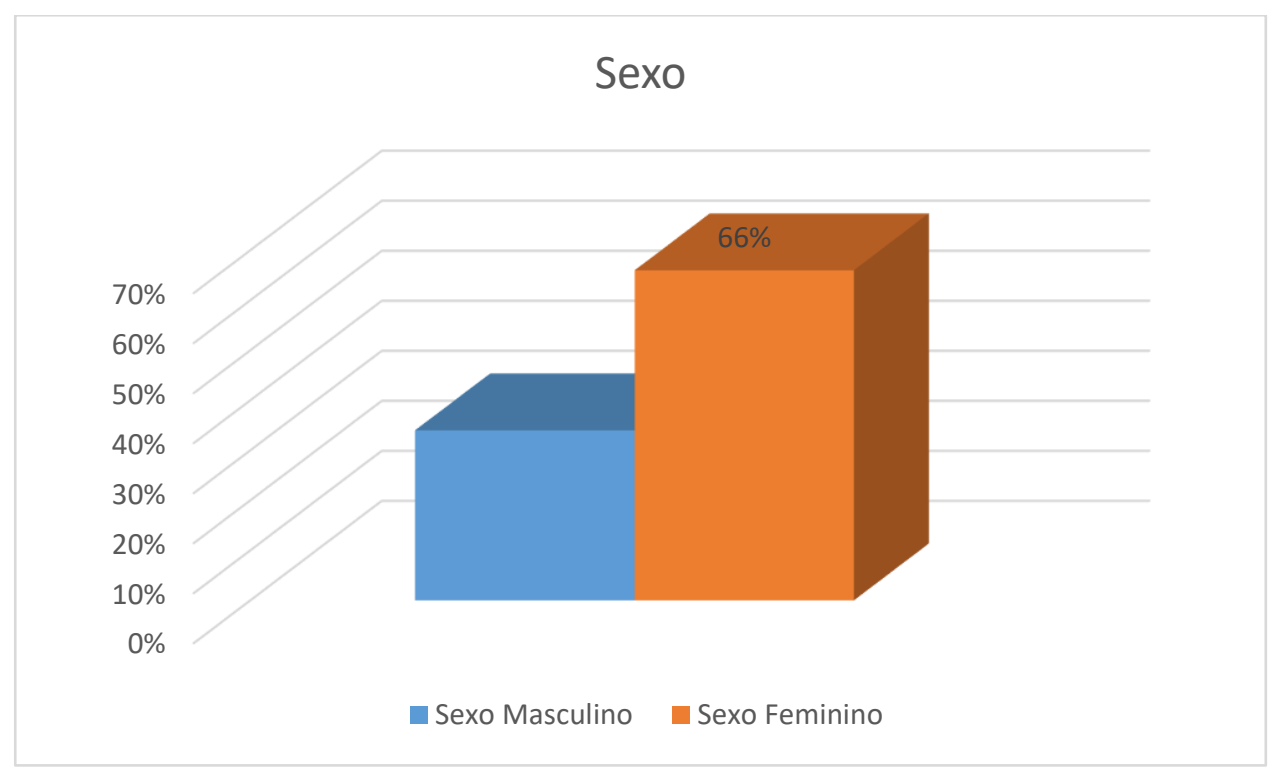

Figura 5

Também foi analisado os clientes da Pizo Store pela faixa etária, isso porque, ao contrário dos outros gráficos, não houve muita diferença na divisão dos consumidores por idade. Tal fato ocorre pela busca constante da diversificação dos produtos oferecidos pela loja, tentando aliar um excelente serviço a uma gama extensa de produtos. Porém pode-se observar (Figura 5) que há um maior interesse do público acima de 29 anos em diante e que dos 43-60 é onde encontrase a maior parcela de clientes atendidos. Tal observação pode ser relacionada ao fato de que pessoas dessa faixa etária já possuem uma maior estabilidade financeira e costumam também dar mais prioridade para gastos relacionados a casa, principalmente assuntos do quesito de decoração. 


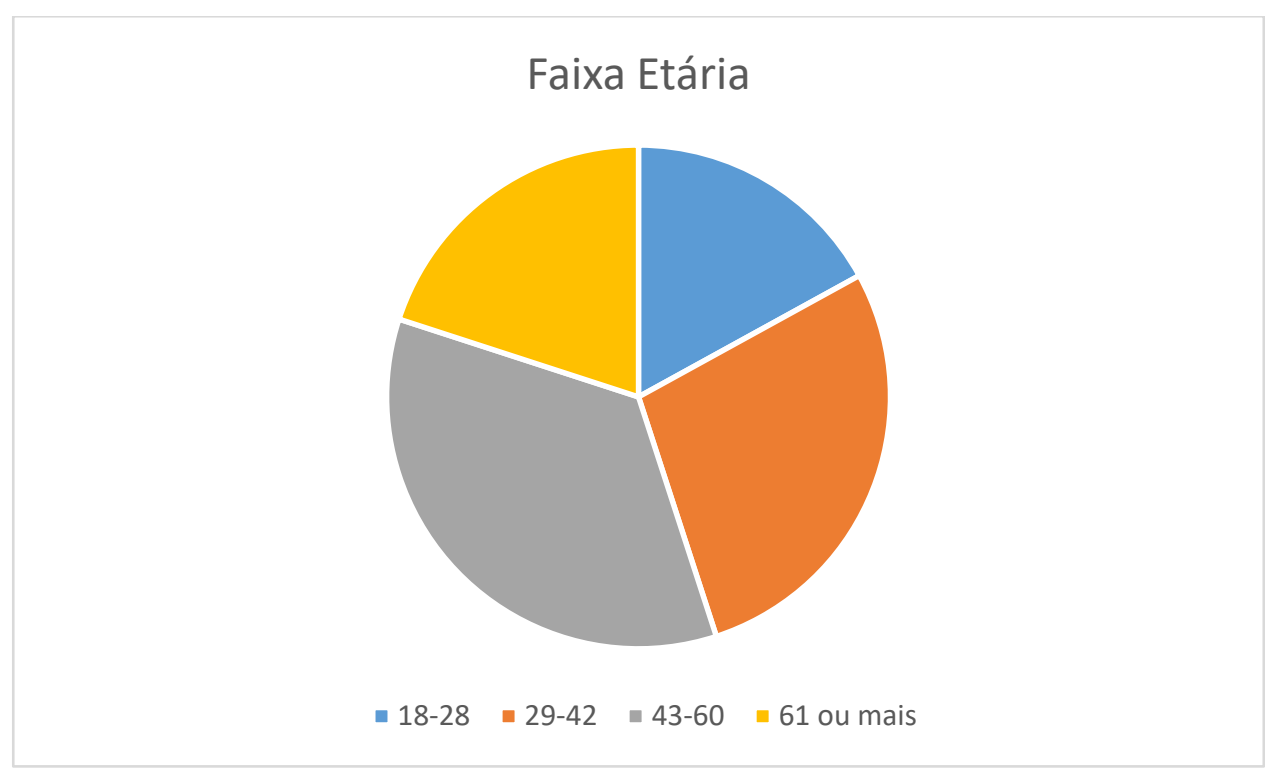

Figura 1

Sendo assim, pode-se concluir que, a partir do cruzamento de dados obtidos por meio do CRM, que os dados são verdadeiros e hígidos, tendo em vista que os resultados caminham para a mesma conclusão.

Tal veracidade dos resultados é de suma importância, pois a partir destes que a Pizo Store irá direcionar suas receitas, bem como sua estratégia de vendas e marketing. 


\section{Conclusão}

No primeiro capítulo foi abordado o histórico e surgimento da sociedade Pizo Store, objeto do presente estudo, contextualizando o cenário do segmento em que a sociedade mencionada atua, bem como seus objetivos e propósitos.

Em seguida, foi apresentado o problema que incentivou o presente trabalho, em como a análise do comportamento dos consumidores, por meio das redes sociais e principais meios de comunicação, pode ser interpretada, a fim de auxiliar as sociedades, de maneira geral, a montarem um plano de marketing efetivo, tudo isso com base nos fatores que levam o consumidor a decisão de compras.

Com isso posto, adentrou-se no referencial teórico, primeiro abordando a história da análise comportamental dos consumidores, desde seu surgimento, passando pelos principais teóricos na área, conceituando as fases que o consumidor passa antes de comprar determinado produto ou serviço, em segundo foi abordado em que foi baseado o plano de marketing da Pizo Store, focando exclusivamente no cliente, acompanhando-o desde a pré-venda a pós-venda.

Após, estabeleceu-se os métodos e métricas necessárias para se obter os dados que embasaram o presente trabalho, tais amostras foram obtidas por meio de ferramentas disponibilizadas pela própria empresa Pizo Store, como, por exemplo, relatórios elaborados ao longo do exercício de 2017 pelo setor administrativo da empresa, bem com a ferramenta CRM comumente utilizada na loja, além de pesquisas com consumidores, conseguidas com formulários específicos para a realização deste trabalho.

Munidos destes dados, foi realizado um cruzamento destes, a fim de traçar o perfil dos consumidores da Pizo Store, com isso saber exatamente em quais consumidores os meios de comunicação e ações de marketings são mais efetivos, que trazem uma maior conversão de orçamentos em vendas efetivas. 
A partir da análise e cruzamento de dados acima, o investimento a ser realizado no plano de marketing da empresa, assim como o retorno gerado por cada canal, observa-se quais canais podem ser explorados de maneira mais eficiente e quais já estão sendo satisfatoriamente eficientes.

Com isso, observou-se que a maior taxa de conversão se dá por meio de revistas de jornais, pois o perfil do consumidor é mais conservador possuindo como principal característica de somente entrar em contato quando possui real interesse em realizar a compra do produto ou serviço, o que se comprova com alta taxa de conversão de orçamento em venda efetiva.

A partir da mesma análise, pode se observar, ainda, que o meio de comunicação menos eficiente é o facebook, pois é o perfil de cliente que possui a pior taxa de conversão. Isso se explica pelo fato dos clientes que deste perfil ter um menor poder de compra, por conseguinte tendo uma das piores taxas de conversão de orçamento em venda efetiva, sendo o meio mais ineficiente.

Logo, levando em consideração o binômio efetividade/custo, pode-se concluir que o melhor investimento são as indicações de consumidores atingidos por meio do site de busca Google, revistas e jornais especializados no segmento, além dos consumidores que procuram a Pizo Store por meio da indicação.

O primeiro se explica pela grande quantidade de consumidores atingidos, 0 que se traduz em um alto retorno, mesmo com uma baixa taxa de conversão de orçamento em venda efetiva, vez que compensada pelo alto número de consumidores atingidos por este meio de comunicação, sendo a melhor forma de investimento, ainda que seja mais alto que os demais.

O segundo se torna um bom investimento, quando o assunto é planejamento de marketing, em razão de sua alta taxa de conversão de orçamentos em vendas, com um custo médio, não muito significativo, além do retorno de receita igualmente médio.

Por último, as indicações. A famosa propaganda feita entre os consumidores, conhecida também como propaganda "boca-a-boca". Tal meio de comunicação indica, quase que imediatamente, dois efeitos, quais sejam o atendimento diferenciado, que é o que a Pizo Store se propõe, e clientes 
satisfeitos, ainda que com pouco tempo desde sua abertura (a sociedade foi constituída em 2017), além disso, pode-se destacar, ainda, o custo baixo no investimento em propaganda, afinal quem a faz são os próprios clientes, a alta taxa de conversão dos orçamentos em vendas, tendo em vista a confiança dos clientes na Pizo Store e a possibilidade de uma margem de lucro maior, já que o investimento em propaganda é quase zero.

Acredita-se, ao final do trabalho, que houve êxito em demonstrar a importância dos meios de comunicação, a fim de se traçar o perfil do consumidor, e assim, oferecer produtos e serviços de acordo com a necessidade de consumidor, tudo isso demonstrado com dados reais de uma empresa em pleno funcionamento e expansão.

Embora tenha sido satisfatório, os resultados e conclusões contidas aqui neste trabalho, não possui a menor intenção de esgotar o tema ou, ainda, estabelecer um conjunto de regras rígidos que devem ser aplicados a todas as empresas, ao contrário, a intenção neste trabalho é chamar a atenção e como a interpretação de dados obtidos dos consumidores, traçando seus perfis, pode melhorar a performance das empresas na venda de seus produtos ou serviços. 


\section{Referências Bibliográficas}

BOONE, Louis E; KURTZ, David L. Marketing contemporâneo. 12. ed. Rio de Janeiro: Cengage Learning, 2009.

CORDEIRO, Mariana Borges. Marketing de Relacionamento para o Mercado Imobiliário: Um estudo do mercado imobiliário da região central de Florianópolis. Programa de Pós-Graduação em Engenharia de Produção, Florianópolis, 2006. 164 p. Disponível em: <https://repositorio.ufsc.br/>. Acesso em: 22.05.2018

CHURCHILL JR., Gilbert A.; PETER, J. Paul. Marketing: criando valor para os clientes. São Paulo: Saraiva, 2000

KOTLER, Philip; KELLER, Kevin Lane. Administração de marketing. 12. ed. São Paulo: Pearson Prentice Hall, 2006.

KOTLER, Philip; ARMSTRONG, Gary. Princípios de marketing. 9. ed. Rio de Janeiro: Prentice Hall, 2003.

LAS CASAS, Alexandre Luzzi. Administração de marketing: conceitos, planejamento e aplicações à realidade brasileira. 1. ed. São Paulo: Atlas, 2012. $528 \mathrm{p}$.

SHETH, Jagdish N.; MITTAL, Banwari; NEWMAN, Bruce I. Comportamento do cliente: indo além do comportamento do consumidor. São Paulo: Atlas, 2001.

SOLOMON, Michael R. O comportamento do consumidor: comprando, possuindo e sendo. 9. ed. Porto Alegre: Bookman, 2011 